The Hiring of an Economist: A Case Study

by

Jessica Holmes, Ph.D.

D avid Colander, Ph.D.

August 2005

MIDDLEBURY COLLEGE ECONOMICS DISCUSSION PAPER NO. 05-19

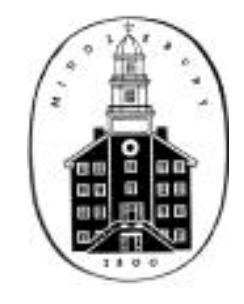

DEPARTMENT OF ECONOMICS

MIDDLEBURY COLLEGE

MIDDLEBURY, VERMO NT 05753

http:/ / www.middlebury.edu/ econ 


\section{The Hiring of an Economist: A Case Study ${ }^{1}$ \\ Jessica Holmes and David Colander \\ Middlebury College}

Textbooks often present markets in an institutional void-there's supply, demand, and equilibrium. Actual markets are much more complicated; while supply and demand forces certainly exist and are central to understanding the market, those forces express themselves through the institutions that have developed. To understand a market is to understand the institutional setting within which it operates. This article is a case study of one particular buyer in the 2005 job market for economists.

The purpose of this article is threefold. First it is to provide information to new entrants into the job market about the institutional setting of the economics $\mathrm{PhD}$ market, information which we believe can save time and money for job seekers, and improve market efficiency. ${ }^{2}$ Second, it is to provide students with a case study that shows how the forces of supply and demand interact with the institutional structure in markets more generally, so that they can put their more esoteric models in context. Third, it is to propose a change in the primary on-line information service, Job Openings for Economists (JOE) (operated by the American Economic Association) that we believe would make the market run more efficiently and lower hiring costs by almost a third.

\section{The Economics PhD Job Market}

The market for $\mathrm{PhD}$ economists is open all year, but most activity takes place between September and April. There are numerous print and online sources for job postings but $J O E$ is the primary source of information. ${ }^{3}$ Listings in $J O E$ cost $\$ 250-\$ 500$, depending upon word count. Over the past five years, 1400-1600 academic jobs have been posted in the JOE annually, with approximately $70 \%$ posted between October and December (Cawley, 2004). The postings lead to a meeting of suppliers and demanders in January at the American Economic Association (AEA) meetings, when face to face job interviews are conducted. Academic job listings that appear in the fall are usually for jobs that begin in September of the following academic year. Nonacademic job listings may be for immediate, spring, summer or fall placement.

\footnotetext{
${ }^{1}$ We would like to thank John Cawley and John Siegfried for helpful comments on an earlier draft of this article.

${ }^{2}$ A number of articles have provided useful discussions of the job market for economists, and provide important background for this case study. These include Barbazat (1992), Carson and Navarro (1988), Cawley (2004), Ehrenberg (2004); List (2000), Siegfried and Stock (1999, 2004), Stock and Alston (2000), and Stock, Alston and Milkman (2000).

${ }^{3}$ Other sources include The Economist magazine and the Chronicle of Higher Education.
} 
The JOE informational service is currently asymmetrical in the sense that demanders list job openings, but there is no comprehensive listing of job searchers. ${ }^{4}$ Many schools do, however, send out lists and maintain websites of their job market candidates, but because these lists and websites are not centrally located, and searchable, they are far less useful than they otherwise would be. ${ }^{5}$ Instead, most often, individuals send applications directly to potential employers who have listed openings in JOE. Let us now consider the individual suppliers and demanders.

\section{The suppliers}

Each year about 900 new PhDs are produced by approximately 100 schools in the U.S. (Siegfried and Stock, 2004; Cawley, 2004). In addition, a small number of foreign $\mathrm{PhDs}$ also enter the US market. Suppliers are often defined by characteristics such as the graduate school they attended, their dissertation advisor(s), fields of specialization, nationality, gender, etc. The majority of sellers in this market are newly minted Ph.D.'s or graduate students in the final throes of their dissertation.

\section{The demanders}

There are three primary groups that hire economists-academic institutions, nonprofit enterprises, and for-profit firms. Each of these is further segmented into various groupings - in academia, there are top ranked $\mathrm{PhD}$ programs, mid level $\mathrm{PhD}$ programs, research liberal arts schools, teaching liberal arts colleges, etc. There are also business schools, medical schools, law schools and public policy schools that hire economists. Non-profit buyers include think tanks, government agencies and non-governmental organizations while for-profit buyers include financial institutions, as well as management, economic and marketing consulting firms. ${ }^{6}$ Jobs come on the market because of deaths, retirements, and expansions of departments and programs.

The creation of positions has its own institutional elements, and in academia, is usually dependent on how many "lines" a department has. The number of lines is loosely related to the demand for the courses taught, but it also depends enormously on institutional politics. Additional lines generally require administrative approval and are rarely, if ever, decided by departments alone. Lines can be either tenure track or nontenure track.

\section{Middlebury's Demand}

Middlebury College is a highly selective private liberal arts college founded in 1800 and located in Middlebury, Vermont. It is regularly listed among the top liberal arts colleges in the nation in the US News and World Report annual survey. The College has

\footnotetext{
${ }^{4}$ We believe that job listings should be symmetrical, with supply ads as well as demand ads allowed in $J O E$. One of the purposes of this article is to advocate that change. (We have suggested to the AEA that they create such a job searchers listing, and they are considering doing so.)

${ }^{5}$ Stock et al (2000) report that $20 \%$ of hiring departments scheduled an interview as a result of these lists. ${ }^{6}$ Among the 2001-2002 Economics PhD graduates, roughly 60\% secured academic jobs, $10 \%$ entered the private sector and $16 \%$ were employed by the government (Siegfried and Stock, 2004).
} 
an enrollment of approximately 2350 undergraduate students from all U.S. states and territories and 68 foreign countries (international students comprise $8.1 \%$ of the student body) and has been coeducational for well over a century. Economics is the largest major at Middlebury and the department has about sixteen full and part-time faculty members.

Middlebury entered the market because of enrollment pressures; it received an additional line because it had the highest student-faculty ratio on campus. The department has a strong tradition of both excellent teaching and strong research, and is generally classified as a research liberal arts school-competing with the other top tier liberal arts schools. Since our primary motivation for hiring was to reduce enrollment pressures, we chose to advertise an "any field" position. ${ }^{7}$ There was little to no disagreement on this choice; ours was a true "any fields" listing because we did not have specific needs-we could easily fit in any person we hired. ${ }^{8}$ We felt that casting a wide net would significantly increase our odds of matching with our ideal candidate: someone with excellent teaching ability, an active and exciting research agenda, and a willingness to settle in rural Vermont.

The position was requested a year ahead, when the department did a study showing its need. The administrative approval came late however, so we did not post a job opening until November. Below you will find our job posting which appeared in the November and December issues of JOE:

\section{Middlebury College, Middlebury, Vermont.}

\section{Any Field}

The Economics Department seeks to hire an economist in any field who can assist in teaching a variety of courses. Specialty is less important than is total excellence in teaching and in research. Appointment will be made at the rank of assistant professor (Ph.D.) or instructor (ABD). The successful candidate will be expected to teach introductory economics, a course in intermediate micro or macro theory and a senior seminar in his/her specialty. Candidates should provide evidence of commitment to excellent teaching in a liberal arts environment and a strong ongoing research program.

Send curriculum vitae, graduate transcripts, three letters of recommendation which address both teaching and scholarship, a short essay directed to our senior majors on your approach to teaching, a copy of at least one piece of scholarly writing and, if available, teaching evaluations. Deadline for receipt of completed applications is December 3, 2004. Interviews will be conducted at the Allied Social Science Association meetings in Philadelphia.

Middlebury College is a residential and coeducational liberal arts institution which has built its reputation on a tradition of outstanding teaching and scholarship and on the academic excellence of its students. Middlebury College

\footnotetext{
${ }^{7}$ Typically, fewer than $10 \%$ of job openings are advertised as "any field" (Cawley, 2004).

${ }^{8}$ Some "all fields" listings are actually looking for a specific field, but the demanders want to survey the market.
} 
is an Equal Opportunity Employer, committed to hiring a diverse faculty to complement the increasing diversity of the student body.

This job ad was fairly boilerplate, with perhaps one exception: the essay directed to senior majors that describes the candidate's teaching philosophy. We included this to help screen out economists who do not rank teaching highly; it both provides information about the candidate's teaching style, classroom strategies and course goals that may not be obvious from teaching evaluations, and increases the marginal (time) cost of sending an application to Middlebury, and thereby screens out candidates who are blanketing schools.

The last statement in the job ad was included to attract minority applicants. Both the College and the department were especially interested in improving the diversity of the faculty (e.g. there are currently no African-American or Hispanic department members). Despite our signal in the job ad, few (if any) candidates signaled their minority status in their applications.

We also required that all candidates send in paper applications, and we refused to consider applications sent to us via email. This was simply done as a screening device to reduce the number of applicants by increasing the cost to them.

In addition to relying on the job ad, we also went through the lists sent to us by graduate schools and invited fifteen especially promising candidates to apply. Invited candidates typically came from highly respected graduate programs, had interesting dissertation topics, and/or attended a liberal arts college as an undergraduate. ${ }^{9}$ Twelve of the fifteen submitted an application (and eight eventually made it to the interview stage). We believe some of these candidates may not have applied without our invitation since liberal arts teaching tends not be emphasized as a job choice at top graduate schools (Colander, 2005)

\section{Narrowing the Field: Reviewing Applications}

Between November 1 and December 23, 2004, Middlebury College received 375 applications for the tenure-track, "any field" position. As noted above, applicants were asked to provide a curriculum vita, graduate transcript, three letters of recommendation, a short essay on teaching, a copy of at least one piece of scholarly writing and, if available, teaching evaluations. About $32 \%$ of the applicants came from graduate programs ranked in the top twenty-five by US News and World Report. More than one-half of the applicants were male (56\%), about one-third (34\%) were female, and $10 \%$ were of unknown gender. ${ }^{10}$ Most fields were well represented, although the pool of applied microeconomists was perhaps the deepest.

Our goal was to interview about thirty applicants at the AEA meetings in January, so we needed to eliminate more than $90 \%$ of the 375 applicants. We reduced the

\footnotetext{
9 Nine of these were from top ten US News and World Report graduate schools.

${ }^{10}$ In 2003, nearly $30 \%$ of $\mathrm{PhD}$ recipients were female and $40 \%$ of new hires at non-PhD granting institutions were female (Cawley, 2004).
} 
candidate pool in a series of rounds. In round one, the chair read through the applications and sorted them into "possibles" and "rejections without deeper consideration". ${ }^{1}$

Approximately one-third of the applicants were rejected at this stage. Those initially rejected were candidates without strong teaching credentials or those whose research was considered pedestrian or not highly interesting. Letters of recommendation were also important at this stage; applicants whose letters contained the following (or similar) comments were easily eliminated during round one:

"He moves at his own pace, which is not very fast, and he tends to be distracted by irrelevant aspects while pursuing a research project."

"... solid, though not outstanding researcher. I can see him publishing his work in $2^{\text {nd }}$ or $3^{\text {rd }}$ ranked field journals."

"Recommend to any economics department outside the top fifty in North America."

"It appears from the evaluations that ---'s teaching needs some work. My thinking is that it is probably a matter of personality and placement..."

In general, most letters of reference were overwhelmingly positive- perhaps too positive. Negative comments were few and far between. Thus, even mild criticism can practically eliminate a candidate's chance of being interviewed at top schools.

Table 1. Percent eliminated, by round (rows sum to approximately $100 \%$ ) (Cumulative percentage in parentheses)

\begin{tabular}{|l|l|l|l|l|l|}
\hline $\begin{array}{l}\text { Graduate } \\
\text { School } \\
\text { Ranking }\end{array}$ & Round 1 & Round 2 & Round 3 & Round 4 & Round 5 \\
& $\begin{array}{l}\text { "Chair } \\
\text { Screening" }\end{array}$ & $\begin{array}{l}\text { "Initial } \\
\text { Department } \\
\text { Screening" }\end{array}$ & $\begin{array}{l}\text { "Secondary } \\
\text { Department } \\
\text { Screening" }\end{array}$ & $\begin{array}{l}\text { "Post ASSA } \\
\text { Interview" }\end{array}$ & $\begin{array}{l}\text { "Post } \\
\text { Campus } \\
\text { Fly-out" }\end{array}$ \\
\hline Top 10 & $\begin{array}{l}2 \% \\
(8 \%)\end{array}$ & $\begin{array}{l}39 \% \\
(47 \%)\end{array}$ & $\begin{array}{l}21 \% \\
(68 \%)\end{array}$ & $\begin{array}{l}29 \% \\
(98 \%)\end{array}$ & $\begin{array}{l}2 \% \\
(100 \%)\end{array}$ \\
\hline Top 11-25 & $26 \%$ & $48 \%$ & $11 \%$ & $14 \%$ & $1 \%$ \\
& $(26 \%)$ & $(74 \%)$ & $(85 \%)$ & $(99 \%)$ & $(100 \%)$ \\
\hline Top 26-50 & $28 \%$ & $\begin{array}{l}58 \% \\
(86 \%)\end{array}$ & $\begin{array}{l}10 \% \\
(96 \%)\end{array}$ & $\begin{array}{l}4 \% \\
(100 \%)\end{array}$ & $\begin{array}{l}0 \% \\
(100 \%)\end{array}$ \\
\hline Top 50 plus & $\begin{array}{l}(28 \%) \\
\end{array}$ & $\begin{array}{l}49 \% \\
(43 \%)\end{array}$ & $\begin{array}{l}5 \% \\
(92 \%)\end{array}$ & $\begin{array}{l}0 \% \\
(100 \%)\end{array}$ \\
\hline
\end{tabular}

One question that many people ask concerns how much graduate school pedigree influences the selection process. In this first stage it mattered a lot. As Table 1 indicates, only $8 \%$ of applicants from top ten schools were rejected in round one compared to $43 \%$ of those from programs outside the top fifty. Clearly, someone coming from a non toptier school has a much harder time making it into the final group than those at a top ten

\footnotetext{
${ }^{11}$ Others in the department were free to pull anyone in the initial rejected pile into the possible pile, but after a few colleagues did random samples of the rejected group, and no changes were made, all accepted his assessment.
} 
school. We suspect that this tendency to focus on top ten schools is even stronger at other similarly-ranked liberal arts schools (List, 2000; Stock et al, 2000; Stock and Alston, 2000). While candidates from top-ranked programs are often the more highly attractive prospects, Middlebury also consciously searches for stand-outs from the middle tiers. We specifically look for bright, well-trained candidates who may have attended a lower ranked school for reasons that are irrelevant to us because such niche candidates are likely to be undervalued by the market.

This information about demander's selection process leads to our first piece of advice to suppliers: Apply to jobs for which you have a reasonable chance of getting.

In our view, at least one half of the candidates should not have applied since their chance of being hired was essentially zero. ${ }^{12}$ Candidates should use the placements of recent alumni as a guide. Alternatively, candidates should look at the graduate schools attended by faculty at the institutions to which they are considering an application. Since the application process is costly for applicants, candidates should spend more time tailoring their applications to the institutions where they have the greatest chance of being hired (e.g. contacting potential collaborators at those departments, identifying courses that would complement the department's current offerings, etc.).

The next step in the process was to narrow the group down again ("round two"). This was done by members of the department interested in reviewing the remaining 256 files. ${ }^{13}$ Each individual was free to choose candidates on whatever criteria they wanted, and they were asked to come to a meeting with a list of favored candidates. At the end of round two, the department identified 69 viable candidates (less than $20 \%$ of the full pool). Surprisingly, there was very little dispute at this stage. The 187 candidates eliminated during round two tended to have less than superb teaching records, weaker letters of recommendation, poorly written job market papers, little chance of completing their dissertation by start of the next academic year, or a combination of the above. We also eliminated marginal candidates whose files were incomplete (particularly those without the requested essay on teaching or whose teaching essay did not demonstrate a concern for teaching and students ). ${ }^{14}$ Again, as Table 1 indicates, candidates rejected in both rounds one and two disproportionately graduated from lower ranked programs; by the end of round two, $47 \%$ of top 10 graduates were eliminated compared to $92 \%$ of applicants from programs outside the top 50.

This leads to further advice regarding the application process:

If you have below-average teaching evaluations, think twice before sending applications to institutions that emphasize teaching as well as research (i.e. those with teaching loads of 2-2 or more).

\footnotetext{
${ }^{12}$ Stock et al (2000) found that $78 \%$ of departments reported receiving a high percentage of applications from unqualified applicants; more specifically, those departments estimated that an average of $52 \%$ of their applicants could be rejected after a cursory examination.

13 More than two-thirds of the department participated in this round.

14 Stock et al (2000) found that $13 \%$ of departments eliminated candidates with incomplete files.
} 
Edit your job market papers carefully. If English is a second language, rely on the academic writing center or peer editors to polish your final draft. This is particularly important for applicants to liberal arts colleges where faculty are expected to contribute to first-year seminars and core courses that emphasize writing.

Don't use a generic cover letter; one size does not fit all. Target each cover letter to the institution to which you are applying (e.g. mentioning your desire to teach graduate courses or work with PhD students signals a poor fit with an undergraduate institution.)

Be sure to complete your application. Candidates with incomplete files are easily eliminated. ${ }^{15}$

In "round three", we divided the remaining applicants into three groups: candidates that all agreed were strong and should be interviewed; candidates that two or more members felt should be interviewed, and candidates that one member of the department felt should be interviewed. Despite the lack of any stated criteria, almost all members of the department agreed on about 15 top candidates. There were another 30 candidates with two or more votes, and another 25 with one department member's recommendation. Nearly all of these candidates had strong teaching evaluations, impressive letters of recommendation, clever and well-written job market papers and complete files.

Numerous criteria aided in the selection of thirty candidates to interview. For example, did the applicant attend or express interest in a liberal arts college; or, did the advisors suggest that this applicant was an ideal match for a top liberal arts college? (If not, the candidate most likely prefers a research institution with lighter teaching loads and readily available graduate assistants.) Can the candidate teach a course not already offered by existing faculty? (While this was an "any field" search, a slight advantage was given to candidates who would diversify our course offerings.) Did the candidate express a geographic preference for rural Vermont? (Middlebury College is located in a town with a population of 8000 and limited opportunities for spousal employment; we gave candidates with stated preferences for Middlebury, Vermont careful consideration.)

While we carefully considered each candidate, department members were especially interested in female candidates because of the shortage of women in the department and the desire to increase the number of female faculty mentors. Thus, while we would always choose the strongest candidate, if we found two candidates equal, we would choose the woman candidate. Additionally, we had a strong preference for increasing the ethnic and racial diversity of the department, so minority candidates (when identified), were given careful consideration.

After evaluation of teaching potential, research ability, and overall fit with Middlebury, the department voted to interview 29 candidates at the AEA meetings. 48\% were from top 10 graduate programs and $83 \%$ were women. Nearly all fields were

\footnotetext{
${ }^{15}$ We did immediately eliminate candidates whose letters of reference were missing. They were given extra time to contact advisors and complete their files.
} 
represented. Among the 29 candidates invited for an interview, four declined, citing a full interview schedule, strong geographical preferences and/or spousal employment concerns.

\section{The Interview}

We scheduled twenty-five interviews over two days. Eight department members participated in the process, with one member in attendance for all twenty-five interviews. We reserved a large suite both to avoid the awkwardness of interviewing in a bedroom and to easily accommodate three to four interviewers and a job candidate. Booking the more expensive suite had a seemingly high return; several female candidates expressed relief upon entering our suite and described the discomfort of sitting on a bed facing three or four (often male) interviewers. For similar reasons, we also ensured that a female faculty member was present in all interviews of female candidates.

Our goal in the interview process was to narrow the field down to two or three candidates with active, interesting and long-term research agendas, charismatic personalities, clear presentation skills and a preference for liberal arts colleges in rural areas ("round four"). At this point, the signaling game, inherent in all markets with imperfect information, intensified. We started every interview with questions about the candidate's research. This not only signaled that Middlebury was a research-focused liberal arts college; it also allowed us to assess the candidate's ability to convey technical information clearly and concisely. Typically, we complimented the candidate on their job market topic and then asked the following questions:

\section{Where do you plan to submit your job market paper?}

We relied on this question to learn about the candidates' expectations for publication and whether the job market paper was ready for submission. Somewhat surprisingly, nearly all candidates planned to send their paper to the American Economic Review. In a few select cases, this was a realistic destination, but for the large majority of candidates, a top field journal would have been the more appropriate answer. Candidates who answered "I haven't thought about it" or "I don't know" signaled that either their papers were not ready for submission or they had not given consideration to appropriate outlets for their research. Those who replied "My advisor hasn't told me yet" revealed a heavy dependence on their advisor for direction.

What do you expect the referees at journal $X$ will say?

This seemingly straightforward follow-up question surprised many candidates. One candidate's response was, "Wow, do you really expect me to tell you everything that is wrong with my job market paper?" No, we wanted candidates to discuss the strengths and weaknesses of their paper without relying on the scripted job market speech. The most successful candidates used this question to clearly articulate their paper's contribution to the literature, identify potential limitations of their work, and suggest extensions for future work.

What will your research agenda look like in 5 years? 
Candidates who successfully answered this question signaled a clear direction for their research and an active agenda beyond the publication of their dissertation. This question separated the graduate students from the soon-to-be assistant professors.

Turning now to teaching, what courses would you like to teach?

In answering this question, candidates typically listed three or four standard courses. When pressed to discuss their "dream course", the most successful candidates enthusiastically described courses not currently offered by our department (e.g. program evaluation; economics of ge nder, race, and class; economics of the law; economics of poverty; public choice). It was clear that they had researched our current offerings and used this question to signal strong teaching complementarities. The candidate who described the graduate seminars she wanted to teach demonstrated a blatant lack of research of our institution (Middlebury College has no graduate program in economics).

What, in particular, attracted you to Middlebury College?

Answers to this question revealed a candidate's level of interest in Middlebury College. Candidates who struggled with this question signaled little interest in the job. Those who successfully answered this question identified particular department members with whom to collaborate, specific interdisciplinary programs with which to affiliate, a strong preference for a research-focused liberal arts college like Middlebury, etc.

\section{Do you have any questions for us about Middlebury?}

This standard question allowed the candidate to ask specific questions about the position. It also revealed whether the candidate had researched the institution prior to the interview. We were most impressed by candidates who asked specific questions about Middlebury (e.g. "I understand you have a January term, can you tell me about the types of courses that are best taught in four weeks?"); or by candidates that relied on this question to reinforce their strengths (e.g. "I recently coauthored a paper with one of my undergraduate students and was happy to see that several of your working papers are faculty-student collaborations. How often do these opportunities arise and does the college value papers co-authored with students?"). Needless to say, we were least impressed by candidates who asked generic questions applicable to any institution or that could be answered by a quick visit to the department or college website (e.g. "how large is the department?", "is there a graduate program?", etc.).

Is there anything you would like us to know that is not on your CV or in your application?

This exit question gave candidates one final opportunity to signal the strength of their match with Middlebury. While many candidates answered "no" to this question, the candidates with the greatest interest in Middlebury College responded with comments such as "I am most interested in research-focused liberal arts colleges and Middlebury College is my top choice", "Middlebury is ideal for me as I have family in the area", "I am an avid skier and snow country appeals to me", "My spouse is self-employed so we have the luxury of not worrying about joint job searches and we love rural areas". 
Body language and engagement with the interviewers also served as important signals. The candidate who continuously looked at his watch was not highly regarded, ${ }^{16}$ nor was the candidate who flirtatiously directed all her answers to the two male interviewers, completely ignoring the women in the room. In the latter case, not only was the candidate's behavior offensive, it raised concerns about differential treatment of male and female students in her classes.

\section{Narrowing the field again: Selecting candidates for a campus visit}

Surprisingly, it was fairly easy to select candidates for a campus visit. A handful of candidates demonstrated interesting and long-term research agendas, charismatic personalities (i.e. outgoing, articulate, with a good sense of humor), strong teaching records and a preference for liberal arts colleges in rural areas. These candidates also behaved more like assistant professors than graduate students; they were obviously prepared to conduct independent scholarly research and command a classroom on their own.

Given the speed with which the market clears, we scheduled our top three candidates for campus visits within the month (no candidates decline our invitation for campus visit). We also informed about five other short-listed candidates of our continued interest and requested that they inform us if faced with a comparable job offer.

\section{The Campus Visit}

Most campus visits are scheduled between January and March. They allow other colleagues and administrators to get to know the candidate and also provide an opportunity for department members to sell the institution to top applicants. While candidates are learning about salary, benefits, promotions, research resources, teaching loads, etc., interviewers are assessing the candidate's fit with the institution (e.g.. will this candidate be an enjoyable colleague? how will (s)he contribute to department activities? how interested is the candidate in this job?) A two-day campus visit to Middlebury typically involves individual (thirty minute) interviews with department members and administrators, lunch with students, dinner with department members and an academic job talk open to the college community.

The most important aspect of the campus visit is the job talk. The candidate to whom we extended our offer stood out among her competitors. She charismatically engaged the audience, convinced us of the importance of her research, demonstrated a strong command of the relevant literature and clearly presented key concepts and empirical results; her slides were clear and concise; her performance was polished and she included sufficient time for questions (which she answered easily and successfully). Aware that both students and administrators would be attending her seminar, she used the opportunity to demonstrate her strong ability to explain technical concepts to noneconomists.

\footnotetext{
${ }^{16}$ This leads to additional advice: schedule enough time between interviews to ensure adequate travel and preparation time (15-30 minutes).
} 
This leads to some advice about the seminar:

Know your audience. If there will be students or non-economists in the audience, tone down the pyrotechnics. Failure to do so signals either little interest in engaging the audience, or an inability to convey technical concepts to non-professionals.

Practice your job talk to ensure that you stay within the allotted time and always leave sufficient time for questions. It is during the Q\&A (more than the canned lecture), that department members assess the breadth and depth of your knowledge and your ability to field questions of all types. Presenting at a professional conference before the opening of the job market will provide you with hints of typical questions or discussion points.

\section{The Offer}

After completion of the three campus visits, the department met to decide to whom we would like to extend an offer. Actually, technically, we were simply recommending to the administration to whom we would like to extend an offer, as the administration had the final say on hiring. At Middlebury, all the negotiations about the offer, including pay, start up funds, moving allowances, and the like, are also handled by the administration.

In making an offer we had to decide how long to give the candidate to decide. That decision is discussed in the department but is actually made by the administration. In this case, we recommended a short time period-one week-since we felt that we had more than one excellent candidate, and did not want to lose another candidate as we were waiting for the candidate to decide. Given this situation we gave her one week to accept the offer and she did, with a slight extension given by the administration to allow some additional negotiations.

The structure of offers presents problems for candidates. While candidates would prefer to receive all job offers simultaneously, the $\mathrm{PhD}$ market rarely affords sellers that luxury. Campus visits are scheduled over a six to eight week period, and offers are typically extended within days of a fly-out. Since most offers are only binding for a week or two, candidates often have to respond before all job options are known. Not surprisingly, this leads candidates to strategically schedule their most preferred campus visits first. ${ }^{17}$ Buyers, aware of the sequential nature of offers and the speed with which the market clears, also tend to schedule their top candidates first, although scheduling difficulties frequently arise. However, like Middlebury, schools generally inform candidates close to the top of their rankings that they are highly ranked and ask that they inform them of any offers, or any invitations to a nearby school, upon which a visit might be piggy-backed.

\footnotetext{
17 The disadvantage of this strategy is that candidates forego the benefits of learning-by-doing (i.e. scheduling the less preferred institutions first).
} 
Table 2: Hiring Costs for one new faculty position

\begin{tabular}{|c|c|c|}
\hline & 2004 Hiring Cost & $\begin{array}{l}\text { Proposed Cost with Computer } \\
\text { Matching }\end{array}$ \\
\hline \multicolumn{3}{|l|}{ Faculty Time } \\
\hline $\begin{array}{l}\text { Value of Faculty Time spent reviewing initial } \\
\text { applications, soliciting candidates from graduate } \\
\text { school lists, selecting candidates to interview at } \\
\text { AEA meetings. }\end{array}$ & $\begin{array}{l}120 \text { hours } * \$ 50 / \text { hour }=\$ \mathbf{6 0 0 0} \\
* 12 \text { faculty spent } 10 \text { hours on average. } \\
\text { (Alternatively, one would arrive at nearly } \\
\text { the same estimate if two faculty members } \\
\text { each reviewed } 6 \text { applications/hour. })^{18}\end{array}$ & $\begin{array}{l}20 \text { hours } * \$ 50 / \text { hour }=\$ \mathbf{1 0 0 0} \\
* 5 \text { faculty search database for } 1 \\
\text { hour then review complete files of } \\
\text { selected candidates for } 3 \text { hours. }\end{array}$ \\
\hline Value of Faculty Time at AEA meetings & $\begin{array}{l}90 \text { hours } * \$ 50 / \text { hour }=\$ \mathbf{4 5 0 0} \\
* 3 \text { faculty } @ 10 \text { hours/day for } 3 \text { days }\end{array}$ & $\begin{array}{l}\mathbf{\$ 4 5 0 0} \\
\text { no change (slight reduction is } \\
\text { possible if matching reduces need } \\
\text { to interview as many candidates) }\end{array}$ \\
\hline $\begin{array}{l}\text { Value of Faculty Time to decide candidates for } \\
\text { campus visits }\end{array}$ & $\begin{array}{l}15 \text { hours } * 50 / \text { hour }=\$ 750 \\
* 15 \text { faculty for } 1 \text { hour meeting }\end{array}$ & $\begin{array}{l}\text { \$750 } \\
\text { no change }\end{array}$ \\
\hline Value of Faculty Time during three campus visits & $\begin{array}{l}24 \text { hours } * \$ 50 / \text { hour }=\$ 1200 \\
* 12 \text { faculty@ } 30 \text { min interviews, } 12 \text { faculty } \\
\text { at } 1 \text { hour seminar, } 3 \text { faculty at } 2 \text { hour } \\
\text { dinner }\end{array}$ & $\begin{array}{l}\$ 1200 \\
\text { no change }\end{array}$ \\
\hline \multicolumn{3}{|l|}{ Department Secretary Time } \\
\hline $\begin{array}{l}\text { Value of Department Secretary Time (e.g. entering } \\
\text { information into database, filing applications, } \\
\text { scheduling interviews, campus visits, etc.) }\end{array}$ & 300 hours $* \$ 15 /$ hour $=\$ \mathbf{4 5 0 0}$ & $\begin{array}{l}50 \text { hours*15/hour }=\$ \mathbf{7 5 0} \\
\text { (elimination of data entry, filing, } \\
\text { etc.) }\end{array}$ \\
\hline \multicolumn{3}{|l|}{ Administration Time } \\
\hline $\begin{array}{l}\text { Administrative Time throughout hiring process (e.g. } \\
\text { position approval, reviewing candidate files, } \\
\text { interviews, attending seminars, contract } \\
\text { negotiations, etc.) }\end{array}$ & 28 hours $* \$ 100 /$ hour $=\$ 2800$ & $\begin{array}{l}\mathbf{\$ 2 8 0 0} \\
\text { no change }\end{array}$ \\
\hline Administration Secretary Time & 4 hours $* \$ 15 /$ hour $=\$ 60$ & $\begin{array}{l}\mathbf{\$ 6 0} \\
\text { no change }\end{array}$ \\
\hline \multicolumn{3}{|l|}{ Miscellaneous Monetary Costs } \\
\hline AEA job advertisement & $\begin{array}{l}\text { \$1000 } \\
* 2 \text { issues@ } \$ 500\end{array}$ & $\begin{array}{l}\text { \$1000 } \\
* \text { this cost may increase slightly } \\
\text { with computer matching }\end{array}$ \\
\hline $\begin{array}{l}\text { AEA meetings monetary costs (i.e. airfare, hotel, } \\
\text { food, ground transportation, etc.) }\end{array}$ & $\$ 4000$ & $\begin{array}{l}\mathbf{\$ 4 0 0 0} \\
* \text { this cost may decrease if a day of } \\
\text { interviewing can be eliminated }\end{array}$ \\
\hline $\begin{array}{l}\text { Three Campus Visits: monetary costs (i.e. } \\
\text { candidates' airfare, hotel, food, ground } \\
\text { transportation, etc.) }\end{array}$ & $\$ 3600$ & $\begin{array}{l}\mathbf{\$ 3 6 0 0} \\
\text { no change }\end{array}$ \\
\hline TOTAL & $\$ 28,410$ & $\$ 19,660$ \\
\hline
\end{tabular}

\section{An Assessment of the Efficiency of the Market and a Proposal for Change}

The costs of hiring are considerable. An estimate of Middlebury's total cost of participating in the 2004 market is $\$ 27,310$. Column (2) in Table 2 contains a breakdown of these costs. This estimate of costs is, of course, only the demander's side of the market. Suppliers incur an additional $\$ 1000$ or so in application and travel costs (Stock et al, 2000).

We believe market efficiency could be improved substantially if the job listings were made symmetrical rather than asymmetrical, and if market were automated to perform preliminary searches. ${ }^{19}$ In our proposed symmetrical market demanders would

\footnotetext{
${ }^{18}$ Stock et al. (2000) found that the average department screened applicants for 94 hours per position (with an average of 170 applications per position).

${ }^{19}$ Any centralized job market has enormous network externalities, and only works if it is relied on by the majority of the market participants. The Illinois Match for Economists has some of the features of our proposed market, but it primarily operates on the second tier market. Few top schools or candidates even
} 
continue to post information about job position, desired field, type of institution, geographic location, field specialization, desired teaching experience, etc. In addition, they would also fill out a questionnaire that would provide metadata for a matching program. This questionnaire would collect much of the information currently found in the advertisement, but could also solicit more detailed information about preferences for teaching vs. research, and desired pedigree.

But in addition to this listing, there would be an alternative listing service for suppliers. They could also place ads about desired jobs, which could be open ads (ads appearing in the on- line or print version of JOE), or blind ads (not appearing in print or on-line, but being considered for the match). We would expect that for the majority of job applicants - those graduating from $\mathrm{PhD}$ programs - that these ads would be open ads submitted by the candidate's university placement office. These postings would advertise information such as field specialization, graduate school, dissertation topic, teaching preferences, etc. (With the AEA supplier postings, the lists currently sent out by universities could be eliminated, since the on-line service would provide much more efficient searching and transmission of information.).

In addition, individuals not associated with graduate schools (such as older professors who might like to move from a university to a liberal arts college, or someone who would like a different geographic location) could also place either blind or open ads specifying their desires. As with the demanders, the ads would be accompanied by a filled out questionnaire (in the case of blind ads, only the questionnaire would be completed) that would provide the metadata for the computer match programs. This questionnaire would have the information provided in the supplier ad, but would also have more specific data about the person's preferences - teaching experience, geographic and institutional preferences (e.g. research or liberal arts), teaching vs. research desires, etc. ${ }^{20}$ We would expect that these ads would be somewhat less expensive than demander ads, with universities paying for their graduates' ads, and individuals paying for their own ads, perhaps at an initial $\$ 50$ listing fee, and a $\$ 20$ or $\$ 30$ per month continual fee for an open ad (published in JOE) and \$10 per month continual fee for a blind ad in which only the questionnaire is filled out.

The advantage of the symmetrical job listing system that we describe is that it allows for the development of a "Job eHarmony" or "Jobmatch.com" for economists. Specifically, computer matching programs could generate tailored lists for both demanders and job candidates at little additional cost, and participants on both sides could purchase such a list. ${ }^{21}$ Once suppliers and demanders are provided with these lists the market could revert to the traditional method, or could be further computerized, with a supplemental links program, with each supplier ad linked to supporting material, such as papers by the candidates, a 20 minute video clip of their teaching, or a 10 minute

think (or know) about this service. Our proposed market would be different; by developing the supplier postings parallel to JOE, and integrating the listings of top tier candidates, it would likely become the primary screening engine and central clearinghouse for all levels of schools and candidates .

${ }^{20}$ This information is not currently directly supplied in applications, and much of it has to be gleaned from between the lines of applications.

${ }^{21}$ One free list per month could come with the job listing, with additional lists costing a small amount. 
summary of their job talk. With such a further computerization, much of the current system could be eliminated, and in-person interviews would be with far better matched candidates, and much more information than currently exists.

This symmetrical computer matching model that we propose has several advantages. First, departments could download candidate information directly from the AEA databank. This would reduce the cost of paper submissions, and save hundreds of hours of data entry and filing. Second, it would improve the matching process and substantially reduce the faculty hours spent reviewing applications (especially given that at least one half of Middlebury's applicants should not have applied). Table 2 suggests that the reduction in time spent reviewing applications, filing and data entry would lower the cost of hiring a faculty member for a demander by almost a third (from $\$ 28,410$ to $\$ 19,660)$. If the supplemental links program is developed, the costs would go down further since far fewer interviews would be necessary.

Third, the market could clear more easily throughout the year (e.g. the JOE is only published 10 times a year); buyers and sellers could submit listings at anytime and could be continuously (and automatically) notified of potential matches. Lastly, it would provide a better mechanism for existing $\mathrm{PhDs}$ to reenter a market that has been traditionally dominated by new entrants, since it would allow better search capabilities, and better information about who is looking for a job.

\section{Conclusion}

The textbook often presents markets as operating costlessly. Supply meets demand and equilibrium results. This case study suggests that actual markets are much different than that, and can be extremely costly. Some of the costs are unavoidable, since demands and supply reflect idiosyncratic elements, which suppliers and demanders would not want to give up. But other elements are avoidable, and efficiency in the market has less to do with supply meeting demand in the textbook fashion, than structuring actual markets to efficiently use technology. Surprisingly, the job market for economists has not done that, and we believe that it is time that it does.

\footnotetext{
${ }^{22}$ Stock et al. (2000) found that the average department screened applicants for 94 hours per position (with an average of 170 applications per position).
} 


\section{References}

Barbezat, D. A. 1992. "The Market for New PhD. Economists" Journal of Economic Education. 23. Summer. 262-76.

Carson, Richard and Peter Navarro. 1988. “A Seller's (\& Buyer's) Guide to the Job Market for Beginning Academic Economists Journal of Economic Perspectives, Spring. 137-148.

Cawley, John. 2004. "A Guide (and Advice) for Economists on the U.S. Junior Academic Job Market." Job Openings for Economists. Oct.

Chen, Yonmin and Terra Mckinnish. 2005. "Do Economics Departments Search Optimally in Faculty Recruiting" Economic Inquiry 43(3):676-688

Colander, David. 2005. "The Making of an Economist Redux" Journal of Economics Perspectives. 19(1): 175-198.

Ehrenberg, Ronald. 2004 "Prospects in the Academic Labor Market for Economists" Journal of Economic Perspectives 18(2):227-238.

Levine, David. "David Levine's Cheap Advice: Going on the Job Market." http://faculty.haas.berkeley.edu/levine/cheap_advice.html\#jobmarket (accessed 7/20/05)

List, John. 2000. "Interviewing Strategies of New PhD. Economists. Journal of Economic Education. 31:2. 191-201

Siegfried, John J and Wendy Stock. 1999. "The Labor Market for New Ph.D.

Economists" Journal of Economic Perspectives. 1(3):115-134.

Siegfried, John, and Wendy Stock, 2004. "The Labor Market for New PhD. Economists in 2002" American Economic Review Papers and Proceedings 94(2):272-288.

Stock, Wendy and Richard Alston. 2000. "Effect of Graduate-Program Rank on Success in the Job Market" Journal of Economic Education. Fall 389-401

Stock, Wendy, Richard Alston and Martin Milkman. 2000. "The Academic Labor Market for Economists: 1995-1996." Atlantic Economic Journal, 28:164-185 